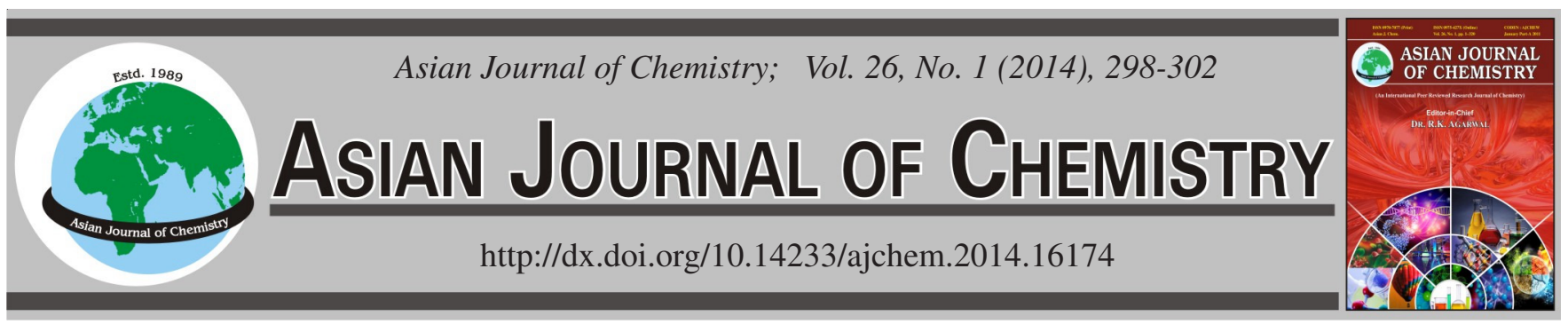

\title{
in vitro Antibacterial Activities of Antibiotics and Traditional Chinese Medicinal Herb Extracts on Escherichia coli and Staphylococcus aureus
}

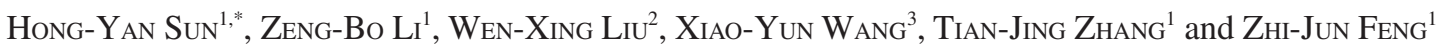

${ }^{1}$ College of Chemical and Biological Engineering, Taiyuan University of Science and Technology, Taiyuan 030021, P.R. China ${ }^{2}$ Department of Agronomy, College of Agriculture and Biotechnology, Zijingang Campus, Zhejiang University, Hangzhou 310058, P.R. China ${ }^{3}$ Institute of Shanxi Soil and Water Conservation, Taiyuan 030045, P.R. China

*Corresponding author: Fax: +86 351 4399509; Tel: +86 13327516187; E-mail: sunhongyan-8@163.com

The present study has been aimed to assess the antibacterial effects of the gentamycin sulfate by agar-well diffusion method against Escherichia coli and penicillin against Staphylococcus aureus. Aspects on the antibacterial mode of action of Chinese medicinal herb extracts have also been characterized. The minimum inhibitory concentration (MIC) of gentamycin sulfate was $8 \mu \mathrm{g} \mathrm{mL}^{-1}$ and those of penicillin was $0.5 \mu \mathrm{g} \mathrm{mL}^{-1}$, with the diameter of inhibition zone was 8.5 and $7.5 \mathrm{~mm}$, respectively. And the rational $\mathrm{pH}$ value of the working antibiotics was 5 , the reasonable preservation temperature should below 80 and $60{ }^{\circ} \mathrm{C}$ for gentamycin sulfate and penicillin, respectively. Meanwhile, both ethanolic extracts of Forsythia suspensa (forsythia) and Taraxacum ohwianum (taraxacum) had a better antibacterial effect to $S$. aureus, however $E$. coli only sensitive to Forsythia suspensa (forsythia). Thus, antibiotics combined with Chinese herb Forsythia suspensa (forsythia) may have better antibacterial effect to bacterium.

Keywords: Antibacterial activity, Antibiotics, Chinese medicinal plants.

\section{INTRODUCTION}

Human beings are often infected by microorganisms such as bacteria, yeasts and viruses in the living environment. And bacteria arised disease and infections become more and more serious these years. Thus to solve these problem has become a hot social issues, especially in medicine and food industry.

Generally, people like to select some antibacterial materials inhibit the growth and multiplication of bacteria. Antibacterial materials contain various natural and inorganic substances, e.g., antibiotics, such as penicillin and gentamycin sulfate. They have antibacterial property specially for Gram-positive Staphylococcus aureus and Gram-negative Escherichia coli, which are known to be common pathogenic bacteria of the skin and intestine, respectively. However, how to rationally use antibiotics is a concern and the increasing antibiotic resistance of some pathogens is another concern ${ }^{1-3}$.

Medicinal plants are another antibacterial materials to bacteria, which have been used as sources of medicine in virtually all cultures ${ }^{4}$. During the last decade, the use of traditional medicine has expanded globally and is gaining popularity. According to WHO, herbal medicines serve the health needs of about $80 \%$ of the world's population, especially for millions of people in the vast rural areas of developing countries $^{5}$. In China, the ancient beliefs and practice of traditional Chinese medicine have been healing people for thousands of years, it is still used by millions of people all over the world even after the development of modern scientific medicine. Chinese herbal medicine contains hundreds of medicinal substances-primarily plants. And traditional Chinese herbal medicine makes almost exclusive use of herbal combinations, more importantly, these formulas are not designed to treat symptoms of a specific illness; rather, they are tailored specifically to the individual according to the complex principles of traditional Chinese medicine. Some of the common uses of the medicinal plants sold in markets include fumigation, vermifuge, pain relief and treating skin infections. Traditional Chinese medicinal plants has received little attention in antibacterial activity research and development. However, the long history of use of medicinal plants in China and its huge biotic riches can be of paramount importance in future research and drug discovery.

In this study, two antibiotics i.e., penicillin and gentamycin sulfate, two species of plants namely forsythia and taraxacum, having traditional claims for the treatment of various disorders were investigated its antibacterial activity and their rational service conditions on Staphylococcus aureus and Escherichia coli strains, which are known to be common pathogenic bacteria 
of the skin and intestine, respectively. These results would be useful to treat infections caused by bacteria and may provide clues to discover a new drug target for therapy bacterial inflammation safely.

\section{EXPERIMENTAL}

Two antibiotics penicillin and gentamycin sulfate and two chinese medicinal herbs namely Forsythia suspensa (forsythia) and Taraxacum ohwianum (taraxacum) were purchased from China national pharmaceutical group corporation, China. These two medicinal herbs plants were harvested and processed and naturally dried, according to traditional procedures.

Bacteria and culture: Two bacteria were kindly provided by China general microbiological culture collection center, they are Gram-positive Staphylococcus aureus (ATCC25922) and gram-negative Escherichia coli (ATCC 25322). The strains were cultured at $37{ }^{\circ} \mathrm{C}$ on plate count agar (PCA) medium.

Preparation of ethanolic extracts: Fresh plant samples were cleaned, freeze-dried in a freeze dry system (Christ 1-4) and ground into a fine powder by a Kenwood Multi-Mill (Kenwood, Havant, UK) and passed through a sieve (24-mesh). Dried plant samples were further air-dried in a ventilated oven at $40{ }^{\circ} \mathrm{C}$ for $24 \mathrm{~h}$, then ground into a fine powder and passed through a sieve as above. Powdered sample (5 g) was extracted with $80 \mathrm{~mL} 95 \%$ ethanol in water at room temperature $\left(\sim 23{ }^{\circ} \mathrm{C}\right)$ for $24 \mathrm{~h}$ in a shaking water bath, followed by $60{ }^{\circ} \mathrm{C}$ for $6 \mathrm{~h}$. The extract was filtered by a Millipore filter with a $0.45 \mu$ m nylon membrane under vacuum at $23^{\circ} \mathrm{C}$. The filtrates were concentrated by rotavapor (R-114) and then freeze-dried by a freeze dry system. The samples were stored at $4{ }^{\circ} \mathrm{C}$ until use.

Experimental designs: In order to determine the minimal inhibitory concentration (MIC) of gentamycin sulfate to $E$. coli and the minimum inhibitory concentration of penicillin to $S$. aureus, gentamycin sulfate was diluted by phosphate buffered saline (PBS, $\mathrm{pH}$ 7.0-7.2) to the final concentration of $0,20,40,60$ and $80 \mu \mathrm{g} \mathrm{mL}^{-1}$ and penicillin concentration of 0 , $0.2,0.4,0.6$ and $0.8 \mu \mathrm{g} \mathrm{mL}^{-1}$.

For determination the effect of different $\mathrm{pH}$ value of antibiotics to antibacterial activity, the $80 \mu \mathrm{g} \mathrm{mL} \mathrm{L}^{-1}$ gentamycin sulfate and $0.8 \mu \mathrm{g} \mathrm{mL}^{-1}$ penicillin was adjusted at $\mathrm{pH}$ value to $3,4,5,6,7,8$ and 9 using $\mathrm{HCl}$ or $\mathrm{NaOH}$ to keep $1 \mathrm{~h}$ and then adjusted back to the primary value to test antibacterial activity, respectively.

For determination the effect of different temperature of antibiotics to antibacterial activity, both $80 \mu \mathrm{g} \mathrm{mL} \mathrm{m}^{-1}$ gentamycin sulfate and $0.8 \mu \mathrm{g} \mathrm{mL} \mathrm{m}^{-1}$ penicillin were under 40, 50, 60, 70, 80,90 and $100{ }^{\circ} \mathrm{C}$ on dry bath incubator kept 0.5 and $1 \mathrm{~h}$, respectively and then cooled back to the room temperature to test antibacterial activity, respectively.

The freeze dried extract samples of herbs were dissolved in phosphate buffered saline solution to the final forsythia concentration of $80,120,160$ and $200 \mathrm{mg} \mathrm{mL}^{-1}$ and the taraxacum concentration of $80,160,240$ and $320 \mathrm{mg} \mathrm{mL}^{-1}$ and sterilized by filtration through $0.22 \mu \mathrm{m}$ sterilizing Millipore express filter (Millex-GP, Bedford, $\mathrm{OH}$ ).

Determination of antibacterial activity: An agar-well diffusion method was employed for determination of antibacterial activities (NCCLS, 1999). Both bacterium were suspended in sterile water and diluted to $\sim 10^{6} \mathrm{CFU} \mathrm{mL}^{-1}$. The suspension $(100 \mu \mathrm{L})$ was spread onto the surface of plate count agar medium. Wells (4.6 $\mathrm{mm}$ in diameter) were cut from the agar with a sterile borer and $60 \mu \mathrm{L}$ prepared antibiotics and extract herbs solutions above were delivered into them. Negative controls were prepared using phosphate buffered saline solution. The inoculated plates were incubated at $35{ }^{\circ} \mathrm{C}$ for $24 \mathrm{~h}$. Antibacterial activity was evaluated by measuring the diameter of inhibition zone (DIZ) of the tested bacteria. Diameter of inhibition zone was expressed in millimeters. All tests were performed in triplicate.

\section{RESULTS AND DISCUSSION}

Minimum inhibitory concentrations of gentamycin sulfate and penicillin to the bacteria: The range of concentrations tested was 0 to $80 \mu \mathrm{g} \mathrm{mL}^{-1}$ and 0 to $0.8 \mu \mathrm{g} \mathrm{mL} \mathrm{m}^{-1}$ for gentamycin sulfate and penicillin, respectively. There was a significant variation in the antibacterial activities (diameter of inhibition zone values) of two antibiotics to the corresponding bacteria. For Gram-negative E. coli, the diameter of inhibition zone values of gentamycin sulfate were between 8.5 and 17.2 $\mathrm{mm}$ and those of penicillin to Gram-positive $S$. aureus were between $7.5 \mathrm{~mm}$ and $17.7 \mathrm{~mm}$ (Fig. 1). Moreover, the gentamycin sulfate concentration less than $8 \mu \mathrm{g} \mathrm{mL} \mathrm{m}^{-1}$ and the penicillin concentration less than $0.5 \mu \mathrm{g} \mathrm{mL}^{-1}$ have no inhibitory activity. So the minimum inhibitory concentration value of gentamycin

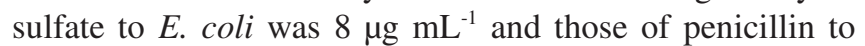

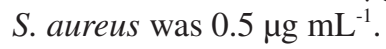
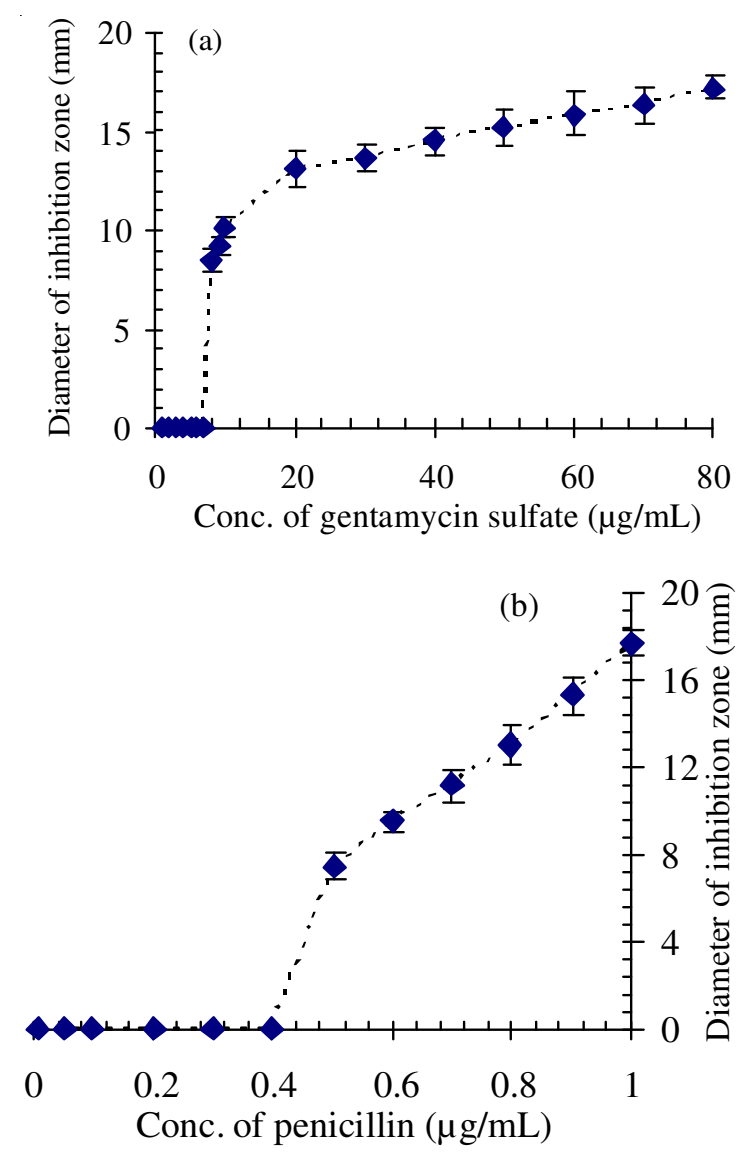

Fig. 1. Antibacterial activity of gentamycin sulfate and penicillin at different concentrations against (a) Escherichia coli and (b) Staphylococcus aureus, respectively. 
Relationship between antibacterial activity and antibiotic concentration: The correlations between antibacterial activity and antibiotic concentration were shown in Fig. 2. In general, with the concentration of antibiotics increased both of the diameter of inhibition zone values also increased. The $\mathrm{R}^{2}$ values of gentamycin sulfate and penicillin concentration for E. coli and and S. aureus was 0.8872 and 0.9956 , respectively.
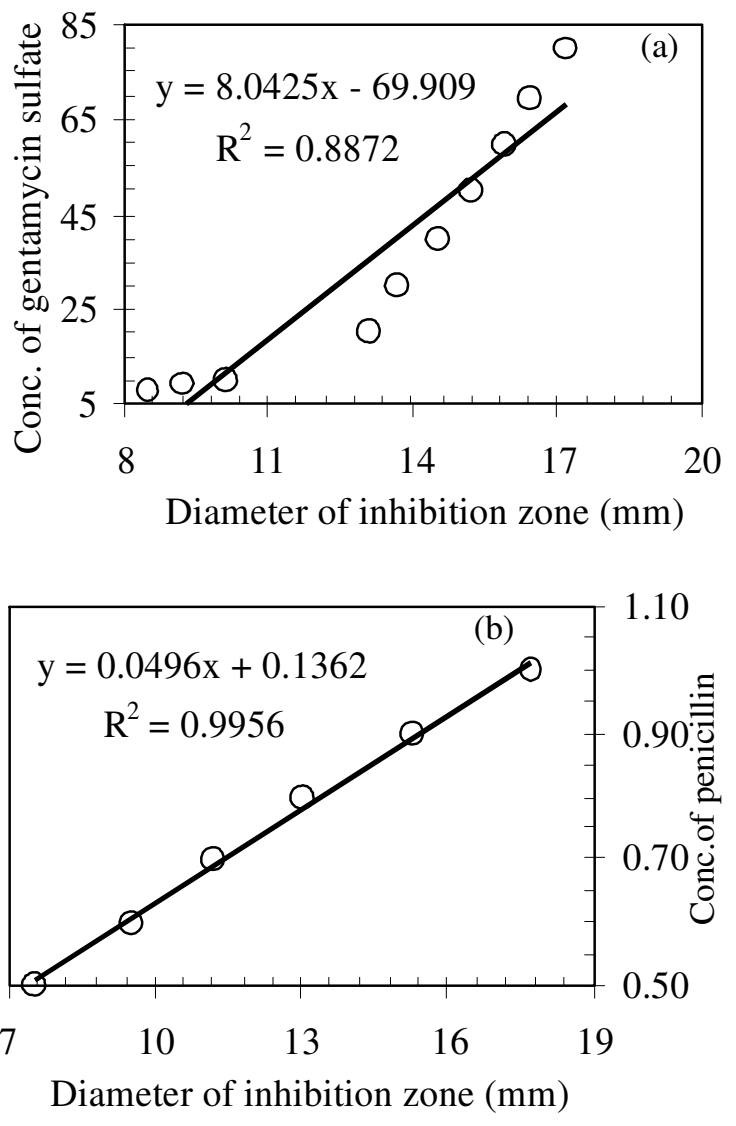

Fig. 2. Relationship between diameter of inhibition zone $(\mathrm{mm})$ and concentration of gentamycin sulfate and penicillin $\left(\mu \mathrm{g} \mathrm{mL} \mathrm{m}^{-1}\right)$ for (a) Escherichia coli and (b) Staphylococcus aureus, respectively

Influence of different $\mathrm{pH}$ value on the antibacterial activity: The effect of different antibiotic $\mathrm{pH}$ value on antibacterial activity was determined (Fig. 3). The diameter of inhibition zone values of both antibiotics against bacteria were increased and then decreased with $\mathrm{pH}$ values from 3 to 9. The diameter of inhibition zone values were between $15 \mathrm{~mm}$ to $17.4 \mathrm{~mm}$ of $E$. coli and $14.1 \mathrm{~mm}$ to $18.9 \mathrm{~mm}$ of $S$. aureus and both of the maximum diameter of inhibition zone value was under the $\mathrm{pH}$ value 5 , indicating the $\mathrm{pH}$ value of the working antibiotics against bacteria should be around 5 .

Influence of different temperature on the antibacterial activity: The effect of different antibiotic temperature on antibacterial activity was determined (Fig. 4). The diameter of inhibition zone values of gentamycin sulfate against $E$. coli decreased along with the increased treatment temperature, the turning point was around $90{ }^{\circ} \mathrm{C}$ and before $80{ }^{\circ} \mathrm{C}$ the difference of diameter of inhibition zone values were not significantly with the value of about $17 \mathrm{~mm}$. However, the change trend of diameter of inhibition zone values of penicillin against
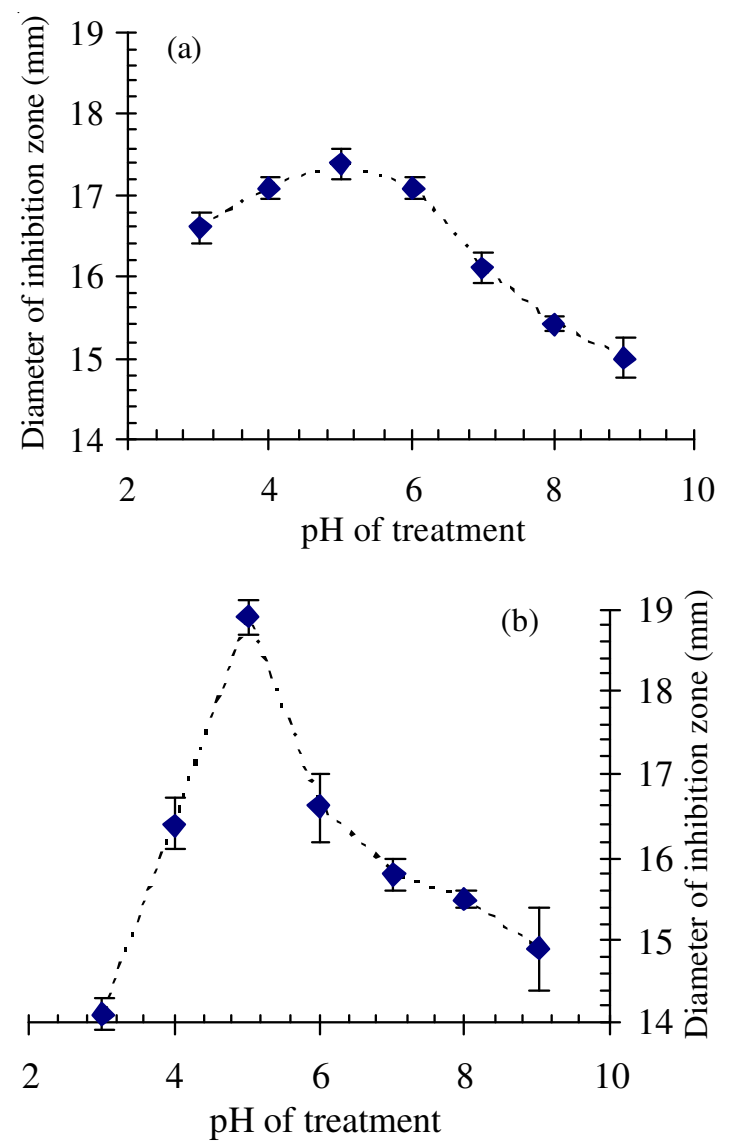

Fig. 3. Antibacterial activity of gentamycin sulfate and penicillin after different $\mathrm{pH}$ values treatment against (a) Escherichia coli and (b) Staphylococcus aureus, respectively
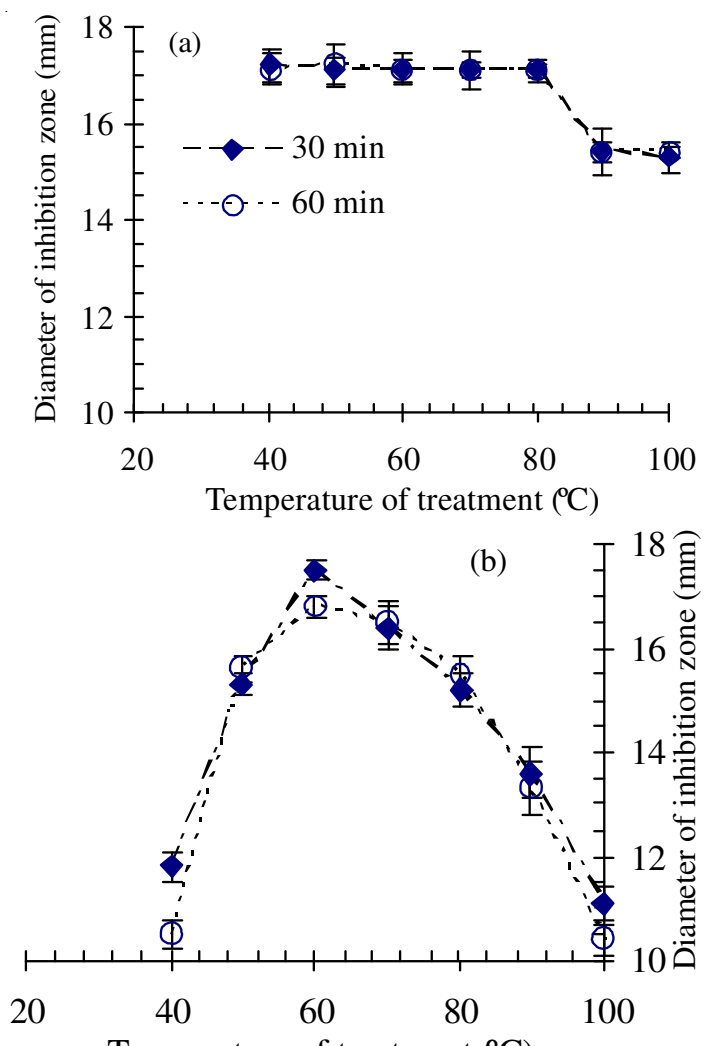

Temperature of treatment $(\mathrm{C})$

Fig. 4. Antibacterial activity of gentamycin sulfate and penicillin after different temperature treatment against (a) Escherichia coli and (b) Staphylococcus aureus, respectively 
$S$. aureus was increased and then decreased with the increased treatment temperature and the maximum diameter of inhibition zone value was $17.5 \mathrm{~mm}$ under the treatment temperature $60{ }^{\circ} \mathrm{C}$. Under two different treatment time, both of the antibacterial activity was no obvious difference, these showed up as the same diameter of inhibition zone value change trend.

Antibacterial activity of forsythia and taraxacum: Two chinese medicinal herbs Forsythia suspensa (forsythia) and Taraxacum Ohwianum (taraxacum) were used to determine their antibacterial activity against $E$. coli and $S$. aureus. There was a significant variation in the antibacterial activities (diameter of inhibition zone values) of the two extracts (Table-1).

\begin{tabular}{cccc}
\multicolumn{4}{c}{ TABLE-1 } \\
\multicolumn{4}{c}{ ANTIBACTERIAL ACTIVITY OF } \\
& FORSYTHIA AND TARAXACUM \\
\hline \multirow{3}{*}{ Test } & $\begin{array}{c}\text { Concentration } \\
\left(\mathrm{mg} \mathrm{mL}^{-1}\right)\end{array}$ & $\begin{array}{c}\text { Escherichia } \\
\text { coli }\end{array}$ & $\begin{array}{c}\text { Staphylococcus } \\
\text { aureus }\end{array}$ \\
\hline \multirow{4}{*}{ Forsythia } & 80 & - & - \\
& 120 & $8.6 \pm 0.21$ & $7.5 \pm 0.23$ \\
& 160 & $12.7 \pm 0.45$ & $11.4 \pm 0.43$ \\
& 200 & + & + \\
\hline \multirow{3}{*}{ Taraxacum } & 80 & - & - \\
& 160 & - & - \\
& 240 & - & $6.5 \pm 0.12$ \\
& 320 & - & $10.4 \pm 0.63$ \\
\hline${ }^{\text {a }}$ Average of three replicates; + indicates complete inhibition and \\
- indicates no inhibition.
\end{tabular}

For $E$. coli, the values of diameter of inhibition zone of forsythia extract was 8.6 and $12.7 \mathrm{~mm}$ under the concentration of 120 and $160 \mathrm{mg} \mathrm{mL}^{-1}$, respectively. Under the concentration of $80 \mathrm{mg} \mathrm{mL}^{-1}$, there was no obvious inhibition. However under the concentration of $200 \mathrm{mg} \mathrm{mL}^{-1}$ the E. coli was completely inhibition. So the minimum inhibitory concentration of forsythia for $E$. coli was $120 \mathrm{mg} \mathrm{mL}^{-1}$. Moreover, the taraxacum extract almost had no inhibition under any concentration.

For $S$. aureus, the values of diameter of inhibition zone of forsythia extract was 7.5 and $11.4 \mathrm{~mm}$ under the concentration of 120 and $160 \mathrm{mg} \mathrm{mL}^{-1}$, respectively. Under the concentration of $80 \mathrm{mg} \mathrm{mL}^{-1}$, there was no obvious inhibition, however under the concentration of $200 \mathrm{mg} \mathrm{mL}^{-1}$ the $S$. aureus was completely inhibition. So the minimum inhibitory concentration of forsythia for $S$. aureus was $120 \mathrm{mg} \mathrm{mL}^{-1}$. Moreover, the diameter of inhibition zone values of taraxacum extract was 6.5 and $10.4 \mathrm{~mm}$, respectively. There was no inhibition under the concentration less than $240 \mathrm{mg} \mathrm{mL}^{-1}$, thus the minimum inhibitory concentration of taraxacum for $S$. aureus was $240 \mathrm{mg} \mathrm{mL}^{-1}$.

Both of the antibiotics tested in this study exhibited high antibacterial activity against the corresponding bacteria and there was a highly positive relationship between the concentration of antibiotics and antibacterial activity. To some extent, these results were similar to those of previous studies. Gentamycin is an aminoglycoside antibiotic that is synthesized by Micromonospora. It is active against most Gram-negative bacteria and some Gram-positive and gentamycin sulfate inhibits bacterial protein synthesis. The combination of the $E$. coli serum antibody and the gentamycin sulfate have been evaluated that the antibacterial activity of gentamycin sulfate increased 1000 times and the clinical curative effect enhanced 100 times than it alone, this means higher efficacy and safety of gentamycin sulfate to eradicate $E$. coli in vitro ${ }^{6}$. The antibacterial activity of standard antibiotics such as ampicillin and cloxacillin was also tested and they showed moderate to good antibacterial activity for $S$. aureus, whereas they were ineffective against $E$. coli and Pseudomonas aeruginosa ${ }^{7}$. Further, this study has shown a link between the concentration of antibiotics and their antibacterial activity and the present result indicated that the minimum inhibitory concentration value of gentamycin sulfate to E. coli was $8 \mu \mathrm{g} \mathrm{mL}^{-1}$ and those of peni-

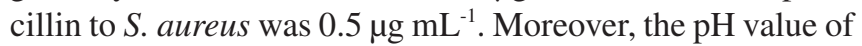
the working antibiotics against bacteria should be around 5 and if the gentamycin sulfate treated higher than $80{ }^{\circ} \mathrm{C}$, its antibacterial activity will be lower, however those of the penicillin was $60{ }^{\circ} \mathrm{C}$. These results may provide certain basis on the preservation and use of antibiotics.

Of the two herb extracts tested in this study, forsythia exhibited high antibacterial activities against both of bacterium, taraxacum only showed antibacterial activities against $S$. aureus. Ethanolic extracts of the compound Chinese medicine with the proportion of the honeysuckle: forsythia: the licorice as 2:2:1 were shown antivirus and antibacterial properties, $S$. aureus, E. coli and Candida albicans were effectively inhibited by them ${ }^{8}$. The activity test indicated that only ethanol extracts of Taraxacum mongolicum exhibited antibacterial activity against some bacteria, such as $S$. aureus and its isolated strain from air, E. coli and P. aeruginosa ${ }^{9}$. However, in this study, the results did not completely follow the trend described above, they indicated that ethanolic extracts of forsythia alone could inhibit both of $S$. aureus and E. coli. Moreover, T. ohwianum (taraxacum) had no antibacterial activity against E. coli, as $T$. ohwianum and T. mongolicum were same different taraxacum species, may be different species had different antibacterial activity.

Our results suggest that Gram-positive bacteria were generally more sensitive to the herb extracts than Gram-negative bacteria. This was consistent with the previous studies on other spices and herbs ${ }^{10-13}$. A possible explanation for these observations may lie in the significant differences in the outer layers of Gram-negative and Gram-positive bacteria, Gram-negative bacteria possess an outer membrane and a unique periplasmic space not found in Gram-positive bacteria ${ }^{14}$. Moreover, both bacterium (S. aureus and E. coli) were more sensitive to forsythia extracts than taraxacum, this suggested that there might be some particular antibacterial substances in forsythia extracts and the exact mechanism should be studied in future research.

\section{Conclusion}

The present study showed that there was obvious antibacterial effect of gentamycin sulfate to $E$. coli with the minimum inhibitory concentration value $8 \mu \mathrm{g} \mathrm{mL}^{-1}$ and those of penicillin to $S$. aureus was $0.5 \mu \mathrm{g} \mathrm{mL}^{-1}$ and the most rational $\mathrm{pH}$ value of the working antibiotics against bacteria should be around 5, the reasonable preservation temperature should below 80 and $60{ }^{\circ} \mathrm{C}$ for gentamycin sulfate and penicillin, respectively. Meanwhile, both ethanolic extracts of Forsythia suspensa (forsythia) and Taraxacum ohwianum (taraxacum) 
had a better antibacterial effect to $S$. aureus, however $E$. coli only sensitive to Forsythia suspensa (forsythia). Thus, antibiotics combined Chinese herb Forsythia suspensa (forsythia) may have better antibacterial efficacy to bacterium.

\section{ACKNOWLEDGEMENTS}

This study was financially supported by the Natural Science Foundation of Shanxi Province of China (2013021031-4) and the Scientific Research Foundation for Doctoral Scholars of Taiyuan University of Science and Technology of China (HY201301). Thanks are also due to the Science and Technology Research Project for Water Conservancy of Shanxi Province (SLT201308).

\section{REFERENCES}

1. J.H. Meng, S.H. Zhao, M.P. Doyle and S.W. Joseph, J. Food Prot., 61, 1511 (1998).

2. V. Perreten, N. Giampa, U. Schuler-Schmid and M. Teuber, Syst. Appl. Microbiol., 21, 113 (1998)
3. F.R. Stermitz, J. Tawara-Matsuda, P. Lorenz, P. Mueller, L. Zenewicz and K. Lewis, J. Nat. Prod., 63, 1146 (2000).

4. S.R. Baquar, in ed.: S. Issaq, The Role of Traditional Medicine in Rural Environment, East Africa Educational Publishers Ltd., Nairobi, pp. 141-142 (1995).

5. World Health Organization, General Guidelines for Methodologies on Research and Evaluation of Traditional Medicine, Geneva, Switzerland, p. 1 (2001)

7. G. Singh, P. Marimuthu, C.S. de Heluani and C. Catalan, J. Sci. Food Agric., 85, 2297 (2005)

6. W. Dong, X.J. Chen, K. Liu, H.T. Chen and Z.L. Sun, Res. Vet. Sci., 91, 136 (2011).

8. J.M. Wang, Sci. China Tech. Sci., 56, 48 (2013).

9. D.M. Gao and Y. Zhang, Phcog. J., 2, 41 (2010).

10. L.L. Zaika, J. Food Saf., 9, 97 (1988)

11. E. Ceylan and D.Y.C. Fung, J. Rapid Meth. Automat. Microbiol., 12, 1 (2004).

12. P. Lopez, C. Sanchez, R. Batlle and C. Nerin, J. Agric. Food Chem., 53, 6939 (2005).

13. B. Shan, Y.Z. Cai, J.D. Brooks and H. Corke, Int. J. Food Microbiol., 117, 112 (2007).

14. C.F. Duffy and R.F. Power, Int. J. Antimicrob. Agents, 17, 527 (2001). 